\title{
Severidade de ocorrência das manchas de alternária e septoriose em girassol semeado em diferentes épocas no Rio Grande do Sul
}

\author{
Luis Henrique Loose ( ${ }^{1 *}$ ); Arno Bernardo Heldwein ('); Ivan Carlos Maldaner ( ${ }^{2}$ ); \\ Dionéia Daiane Pitol Lucas (1); Fernando Dill Hinnah ('); Mateus Possebon Bortoluzzi (1) \\ (') Departamento de Fitotecnia, Universidade Federal de Santa Maria (UFSM), 97105-900 Santa Maria (RS), Brasil. \\ (2) Instituto Federal de Educação, Ciência e Tecnologia Farroupilha, 97420-000 São Vicente do Sul (RS), Brasil. \\ (*) Autor correspondente: luisloose@yahoo.com.br
}

Recebido: 15/ago./2011; Aceito: 27/jan./2012

\section{Resumo}

A cultura do girassol tem recebido grande atenção em razão de suas características agronômicas e a possibilidade de inclusão nos sistemas de rotação de cultura. No entanto, as diferentes condições meteorológicas do período de cultivo determinam a ocorrência ou não de doenças, de modo que este conhecimento é fundamental para a escolha do melhor período de cultivo. Este trabalho teve por objetivo determinar a severidade de ocorrência das manchas de Alternária e septoriose em girassol (Helianthus annuus) semeado em diferentes épocas. Utilizou-se o delineamento inteiramente casualizado, bifatorial ("épocas de semeadura" x "híbridos de girassol”) em quatro anos agrícolas de 2007 a 2011 , em Santa Maria (RS). As medições fenométricas e as determinações de severidade das manchas de Alternária e septoriose foram feitas uma e duas vezes por semana, respectivamente. Obteve-se a severidade final observada (SVFO), e foram calculadas as variáveis área abaixo da curva de progresso da doença (AACPD) e dias com área foliar sadia (DAFS). Nos anos agrícolas de 2007/2008, 2008/2009 e 2010/2011, a severidade das doenças foi menor para as primeiras épocas de semeadura, de agosto a setembro, enquanto nas épocas tardias a tendência foi de aumento da severidade. Para 2009/2010, ano sob influência de El Niño, com chuvas acima da média, todas as épocas de semeadura tiveram alta severidade, com destaque negativo para as primeiras épocas, pois são nessas que se concentram os maiores volumes de chuvas em anos sob influência desse fenômeno. Portanto, semeaduras tardias ou em anos de El Niño são propícias à alta severidade de manchas de Alternária e septoriose em girassol, devendo ser evitada a semeadura nessas condições.

Palavras-chave: Helianthus annuus, manchas foliares, épocas de semeadura, doenças, chuva, El Niño.

\section{Alternaria and septoria leaf spot severity on sunflower at different sowing dates in Rio Grande do Sul State, Brazil}

Abstract

The sunflower cultivation has received great attention because of their agronomic characteristics and the possibility of inclusion in crop rotation systems. However, the different climatic conditions prevailing in the growing season determine the occurrence or not of the disease, so that this knowledge is critical for choosing the best growing season. This study aimed to determine the severity of Alternaria and Septoria leaf spots on sunflower (Helianthus annuus) at different sowing dates. Experiments were carried out during four seasons, from 2007 to 2011, in Santa Maria, state of Rio Grande do Sul, Brazil. The experiments had a completely randomized design with two-factor (sowing dates vs. sunflower hybrids). The measurements of plant growth and severity of leaf spots caused by Alternaria and Septoria were taken once and twice a week, respectively. The final severity (SVFO) and the variables area under the disease progress curve (AACPD) and days of healthy leaf area (DAFS) were determined and used for comparing hybrids and sowing dates. In the crop seasons of 2007/2008, 2008/2009 and 2010/2011, the severity of disease was lower for early sowing dates from August to September, while the later ones tended to increase the disease severities. In 2009/2010 growing season, period under El Niño influence and with rainfall above normal, all sowing dates resulted in high disease severity, especially negative for the first sowing dates because of the highest rainfall in years under the phenomenon influence. Therefore, the late sowing or sowing during El Niño years are favorable to high Alternaria and septoria leaf spots severity in sunflower crop and then the sowing should be avoided under those conditions.

Key words: Helianthus annuus, leaf spots, sowing dates, diseases, rainfall, El Niño. 


\section{INTRODUÇÃO}

O girassol é uma planta dicotiledônea, pertencente à família Asteraceae, espécie Helianthus annuus L. cultivada em todos os continentes. Destaca-se na produção de óleo comestível, sendo apontada também como de grande potencial na produção de biodiesel e de cosméticos. Possui características agronômicas importantes, como baixa sensibilidade ao fotoperíodo, maior resistência à seca, ao frio e ao calor do que a maioria das espécies anuais de importância econômica cultivadas no Brasil (LEITE et al., 2007). É também uma alternativa técnica e economicamente viável em sistemas de rotação de culturas.

No Brasil, a produtividade média do girassol vem se mantendo em torno de $1300 \mathrm{~kg} \mathrm{ha}^{-1}$ nas cinco últimas safras (CONAB, 2011), ocorrendo variações entre anos decorrentes das condiçôes meteorológicas. Essa produtividade é baixa em comparação com a produtividade argentina (Sira, 2010), que gira em torno de $1900 \mathrm{~kg} \mathrm{ha}^{-1}$. Um dos principais fatores da produtividade do girassol é a ocorrência de doenças fúngicas (Leite e AMorim, 2002b). Um exemplo típico ocorreu em 1983 no Estado do Paraná, cuja produtividade média do girassol foi de apenas $460 \mathrm{~kg} \mathrm{ha}^{-1}$ devido à ocorrência intensa de doenças fúngicas, principalmente Sclerotinia sclerotiorum (Dall'Agnol et al., 2005).

As manchas de Alternária (Alternária helianthi (Hansf.) Tubaki e Nishihara, Alternáriaster helianthi (Hansf.) E.G. Simmons) e septoriose (Septoria helianthi Ellis e Kellerman) são duas das principais doenças fúngicas do girassol que ocorrem no mundo. Ambas as doenças foliares, sob condiçōes meteorológicas favoráveis ao seu desenvolvimento, tornam-se altamente severas ao girassol (Block, 2005; Dall'Agnol et al., 2005; Leite, 2005), havendo diferença de progresso de densidade de lesóes e de severidade entre híbridos (Leite e Amorim, 2002a).

Essas doenças causam a redução da taxa fotossintética, devido à formação de manchas foliares necróticas que promovem a senescência precoce de folhas e antecipam a maturação das plantas severamente afetadas (RibeIro et al., 1974; Leite, 2005). Em decorrência a essas doenças e sua severidade, ocorre reduçáo da produtividade de aquênios, do número de aquênios por capítulo, da massa média dos aquênios e do teor de óleo (OrTa et al., 2002; BLOCK, 2005).

Os principais elementos meteorológicos que afetam a interação entre patógeno e planta são a temperatura do ar e a umidade relativa do ar (Leite e Amorim, 2002a; Agrios, 2004; Bosco et al., 2009). Porém, a maioria dos patógenos necessita água líquida sobre a superfície das folhas para completar o processo de infecção com sucesso (Huber e Gillespie, 1992). Dessa forma, o aumento da duração do período de molhamento foliar decorrente da condição de precipitação pluvial abundante e alta umidade relativa do ar, favorecem o desenvolvimento e a maior severidade de ocorrência das manchas foliares (HELDwEIN et al., 2007). No caso da mancha de Alternária, alta umidade relativa e temperatura entre 25 e $30{ }^{\circ} \mathrm{C}$ são condiçôes ótimas para sua ocorrência (SENTELHAs et al., 1996), associadas à ocorrência de elevadas precipitaçôes pluviais (Dudienas et al., 1998). Essa relação de ambiente favorável com hospedeiro suscetível associado à presença de inóculo resulta na ocorrência das doenças.

As manchas foliares ocorrem em todas as épocas de semeadura e regióes produtoras de girassol (Leite e AMOrim, 2002a). Entretanto, sua severidade depende das condiçóes meteorológicas, que variam com a época de semeadura e o local em que a cultura foi semeada. Apesar de haver épocas de semeadura indicadas para cada região, muitos agricultores têm optado pela semeadura do girassol em épocas alternativas (Silveira et al., 2005), o que pode favorecer ou não o desenvolvimento das doenças. Nesse contexto, ainda faltam determinaçóes mais claras e precisas para os produtores de girassol na Região Central do Rio Grande do Sul.

O presente estudo teve por objetivo determinar a severidade da mancha de Alternária e septoriose na cultura do girassol, semeada em diferentes épocas em Santa Maria (RS).

\section{MATERIAL E MÉTODOS}

Os experimentos foram realizados em Santa Maria (RS) (latitude: $29^{\circ} 43^{\prime} 23^{\prime \prime}$, longitude: 5343'15"O e altitude: $95 \mathrm{~m}$ ), região da Depressão Central do Rio Grande do Sul. Considerando a classificação de Köppen, o clima regional é do tipo $\mathrm{Cfa}$, subtropical úmido com veróes quentes, sem estaçáo seca definida (HeLdwein et al., 2009). O solo da área experimental é classificado como Argissolo Vermelho Distrófico arênico (EMBRAPA, 2006) e pertence à Unidade de Mapeamento São Pedro.

Realizaram-se quatro experimentos de épocas de semeadura de girassol durante quatro anos agrícolas, em delineamento inteiramente casualizado com quatro repetiçōes, sendo bifatoriais, cujo fator "A" corresponde às épocas de semeadura e o fator " $D$ " aos diferentes híbridos de girassol. As épocas constaram de semeaduras realizadas no início de cada mês, no período de agosto a fevereiro. Nos anos agrícolas de 2007/2008, 2008/2009, 2009/2010 e 2010/2011 foram realizadas, respectivamente, sete (agosto a fevereiro), cinco (agosto a novembro e fevereiro), seis (agosto a janeiro) e duas (novembro e dezembro) épocas de semeadura. Entretanto, foram perdidas as parcelas do híbrido Hélio 358 ( $\mathrm{Hl}$ 358) nas épocas de agosto e setembro do ano agrícola de 2009/2010, restando apenas o híbrido Aguará 03 (Ag 03) e, portanto, para o teste de comparação de médias foram analisadas apenas quatro épocas. Para os três primeiros experimentos, foram utilizados os híbridos $\mathrm{Ag} 03$ e $\mathrm{Hl}$ 358, substituindo-se o híbrido $\mathrm{Hl}$ 
358 pelo Hélio 251 (Hl 251) no último ano agrícola por falta de disponibilidade de sementes. Os três híbridos são de ciclo precoce. O tamanho das parcelas utilizado foi de 4,5 x $5 \mathrm{~m}$, com área útil para avaliaçáo das doenças de 8,1 $\mathrm{m}^{2}$ com duas repetiçóes para cada híbrido.

A área experimental foi preparada no sistema convencional com aração e gradagem. A adubação seguiu as recomendações para a cultura do girassol com base na análise química do solo (CQFS, 2004). Utilizou-se o espaçamento entre linhas de $0,90 \mathrm{~m}$ e na linha de semeadura de 0,25 $\mathrm{m}$, resultando em uma população de 44.444 plantas $\mathrm{ha}^{-1}$.

Plantas daninhas e pragas foram controladas sempre que necessário, por capina manual e por uso do inseticida lambda-cialotrina + tiametoxam recomendado para a cultura (Engeo Pleno) respectivamente. Salienta-se que não houve aplicação de fungicidas em nenhum período dos experimentos, justamente para se verificar a ocorrência natural e severidade de doenças em função das épocas de semeadura. A inoculaçáo dos patógenos ocorreu de forma natural, sem introdução artificial.

Semanalmente foram realizadas as mediçóes de largura de cada folha de 16 plantas por época e estimada a área foliar pela equação 1 (MALDANER et al., 2009), determinando-se posteriormente o índice de área foliar (IAF).

$\mathrm{AF}=1,7582^{*}(\mathrm{~L})^{1,7069}$

em que, AF é área foliar de uma folha $\mathrm{em}^{\mathrm{cm}^{2}}$ e L é a largura máxima do limbo foliar da folha de girassol mensurada em $\mathrm{cm}$.

Observaçôes de severidade causada pelas manchas de Alternária e septoriose foram feitas conjuntamente, duas vezes por semana em quatro plantas marcadas por parcela, determinando-se a porcentagem da área de tecido doente pelo método direto de avaliação visual, utilizando-se a escala diagramática desenvolvida por LeITe e AMORIm (2002b). A severidade de cada parcela foi obtida pela média das quatro plantas observadas, enquanto a severidade do híbrido corresponde à média das quatro repetiçóes.

Obtidos os dados médios da severidade observada de cada tratamento, determinou-se a severidade final observada (SVFO) e a duração da área foliar sadia (DAFS) obtida a partir da integração do índice de área foliar sadia (WagGoner e BERger, 1987). Calculou-se a área abaixo da curva de progresso da doença (AACPD), a partir da integração das curvas de progresso da doença e da duração da área foliar sadia. Quanto maior o valor de DAFS e menor os valores de SVFO e AACPD, menor o nível de injúria causada pela doença. A AACPD e DAFS foram calculadas conforme descrito por CAMPBell e Madden (1990):

$$
\operatorname{AACPD}=\sum_{i=1}^{n-1}\left(\frac{x_{i}+x_{i+1}}{2}\right)\left(t_{i+1}-t_{i}\right)
$$

$D A F S=\sum_{i=1}^{n-1}\left[\frac{\operatorname{IAF}_{i}\left(1-x_{i} / 100\right)+\operatorname{IAF}_{i+1}\left(1-x_{i}+1 / 100\right)}{2}\right]\left(t_{i+1}-t_{i}\right)$

em que, $\mathrm{n}$ é o número de avaliaçôes, $\mathrm{x}$ a severidade $\mathrm{da}$ mancha de Alternária e/ou septoriose em \%, $\left(t_{i+1}-t_{i}\right)$ representam o intervalo de tempo (em dias) entre as avaliaçôes consecutivas de severidade e $\mathrm{IAF}_{\mathrm{i}}$ é o índice de área foliar no tempo i.

Os valores de AACPD foram padronizados, dividindo-se cada um de seus valores pelo número de dias da epidemia. As variáveis analisadas estatisticamente foram a SVFO, AACPD e DAFS entre os híbridos e épocas e o efeito da interação entre os fatores. Os resultados verificados nos diferentes tratamentos foram submetidos à análise de variância pelo teste de $\mathrm{F}$ e a diferença entre as médias foi comparada pelo teste de Tukey $(\mathrm{p}<0,05)$. Para essas análises estatísticas, os valores de severidade foram transformados em arc sen $(0,01 \mathrm{x})^{-0,5}$, transformação usada nos casos em que o dado observado é uma proporção (entre 0 e 1) e segue distribuição binomial com número $\mathrm{N}$ de observaçôes, comuns para todas as unidades experimentais. Foram feitos os desdobramentos do fator A (épocas de semeadura) dentro de cada nível do fator D (híbrido) nos casos em que houve interação significativa. Quando a interação não foi significativa, desdobraram-se os valores médios de ambos os híbridos para épocas. O coeficiente de variação (CV) de cada experimento e a diferença mínima significativa (DMS) foram utilizados para a classificação dos experimentos (CARgnelutti e STORCK, 2007).

A partir dos dados dos quatro anos de experimentos, foram separados os anos sem El Niño (2007/2008, 2008/2009 e 2010/2011) do ano sob El Niño (2009/2010), obtendo-se a média, o desvio-padrão e a linha de tendência dos valores de SVFO, AACPD e DAFS para as épocas de semeadura. Salienta-se que as épocas de agosto e setembro de 2009/2010 contaram apenas com o híbrido Ag 03, enquanto as demais foram valores médios para os dois híbridos. Ademais, foram feitas análises de regressão entre a área abaixo da curva de progresso da doença e as seguintes variáveis meteorológicas: precipitaçâo pluvial acumulada, média da temperatura máxima diária e média da temperatura média diária, obtidas para o período correspondente ao ciclo de cada época, na estação meteorológica automática do Instituto Nacional de Meteorologia, distante $50 \mathrm{~m}$ da área experimental.

\section{RESULTADOS E DISCUSSÃO}

Os resultados da evolução da severidade observada da mancha de Alternária e septoriose no ciclo do girassol durante o ano agrícola de 2007/2008 sáo apresentados na tabela 1. Observa-se que a interação $(\mathrm{AxD})$ é significativa 
apenas para o DAFS. Para SVFO e a AACPD não ocorreu interação significativa entre os fatores. A época de outubro foi a de menor valor de SVFO, não diferindo das épocas de agosto e setembro (Tabela 1). A maior severidade ocorreu para a época de janeiro, a qual não diferiu estatisticamente de fevereiro. O maior valor de DAFS foi observado na semeadura de setembro, tanto para o híbrido Ag 03 quanto para o híbrido $\mathrm{Hl}$ 358; os menores valores foram anotados para as épocas de janeiro e fevereiro, evidenciando que o DAFS está diretamente relacionado ao IAF, o qual apresenta menores valores para estas épocas em razão da redução do ciclo da cultura em respostas à temperatura do ar. (Tabela 1). A época de semeadura com a menor AACPD foi a de outubro, enquanto a maior AACPD ocorreu na semeadura de janeiro. Assim, para o ano agrícola de 2007/2008, as três primeiras épocas de semeadura tiveram a menor severidade de ocorrência da mancha de Alternária e septoriose em relação às épocas mais tardias. Esse resultado, provavelmente, pode ser em decorrência da maior temperatura e possivelmente da alta umidade do ar ocorrida no estádio vegetativo do girassol semeado nessas épocas, proporcionando melhores condições de infecção pelos patógenos (HELDWEIN et al., 2007).
Para o ano agrícola de 2008/2009, assim como no anterior, a SVFO e a AACPD não tiveram interação $(\mathrm{AxD})$ significativa, enquanto no DAFS a interaçáo foi significativa. A SVFO teve o menor valor para a época de setembro, enquanto o maior valor ocorreu para a época de outubro (Tabela 2). A época em que a AACPD teve o menor valor foi a de SET, enquanto a época de maior AACPD foi a de outubro. Quanto a DAFS os resultados foram bastante contrastantes entre os híbridos. Para o híbrido Ag 03, os maiores valores ocorreram nas épocas de outubro e agosto, não diferindo entre si estatisticamente, e os menores na semeadura de novembro. O híbrido $\mathrm{Hl} 358$ foi o de maior valor de DAFS para a semeadura de fevereiro não diferindo de outubro, enquanto o menor valor ocorreu para a semeadura de novembro. Enquanto a SVFO e a AACPD foram maiores para as épocas de outubro, o DAFS também foi maior nessa época, sendo um resultado oposto ao esperado. Esse fato pode ser explicado em função da forte precipitaçáo de granizo ocorrida em 8/1/2009, a qual atingiu as épocas de outubro e novembro, além de dezembro a janeiro, que foram completamente perdidas, respectivamente, por danos nas plantas e pelo excesso hídrico na emergência. As plantas da época de outubro estavam no

Tabela 1. Severidade final observada (SVFO), dias de área foliar sadia (DAFS) e área abaixo da curva de progresso da doença (AACPD) para a mancha de Alternária e septoriose na cultura do girassol, em diferentes épocas de semeadura dos híbridos Aguará 03 (Ag 03 ) e Hélio 358 (Hl 358). Santa Maria, ano agrícola 2007/2008

\begin{tabular}{|c|c|c|c|c|}
\hline \multirow{2}{*}{ Época } & \multirow{2}{*}{$\begin{array}{c}\text { SVFO (\%) } \\
\text { Ambos híb. }\end{array}$} & \multicolumn{2}{|c|}{ DAFS (dias)** } & \multirow{2}{*}{$\begin{array}{c}\text { AACPD } \\
\text { Ambos híb. }\end{array}$} \\
\hline & & Ag 03 & HI 358 & \\
\hline Agosto & $15,95 a^{*}$ & 103,88 bc & $103,64 b$ & $258,29 b$ \\
\hline Setembro & 13,73 a & $128,23 \mathrm{a}$ & $116,41 \mathrm{a}$ & $227,48 b$ \\
\hline Outubro & 13,31 a & $95,35 \mathrm{~d}$ & $93,94 \mathrm{~d}$ & 88,17 a \\
\hline Novembro & $30,31 \mathrm{~b}$ & $106,65 b$ & $99,05 \mathrm{c}$ & $502,16 \mathrm{c}$ \\
\hline Dezembro & $32,04 \mathrm{~b}$ & $101,18 \mathrm{c}$ & $79,25 \mathrm{e}$ & $610,21 \mathrm{~cd}$ \\
\hline Janeiro & $50,01 \mathrm{c}$ & 86,16 e & $67,37 \mathrm{f}$ & 1201,91 e \\
\hline Fevereiro & $44,56 \mathrm{c}$ & $66,48 \mathrm{f}$ & $52,44 \mathrm{~g}$ & $717,57 \mathrm{~d}$ \\
\hline CV (\%) & 12,77 & & & 17,21 \\
\hline DMS & 7,99 & & & 194,03 \\
\hline
\end{tabular}

* Médias seguidas da mesma letra na linha não diferem entre si pelo teste Tukey (p>0,05). ** Interação entre fator A (épocas) e D (híbridos) significativa pelo teste Tukey $(\mathrm{p}<0,05)$ e "A" é desdobrado dentro de " $\mathrm{D}$ ".

Tabela 2. Severidade final observada (SVFO), dias de área foliar sadia (DAFS) e área abaixo da curva de progresso da doença (AACPD) para a mancha de Alternária e septoriose na cultura do girassol, em diferentes épocas de semeadura dos híbridos Aguará 03 (Ag 03 ) e Hélio 358 (Hl 358). Santa Maria, ano agrícola 2008/2009

\begin{tabular}{|c|c|c|c|c|}
\hline \multirow{2}{*}{ Época } & \multirow{2}{*}{$\begin{array}{c}\text { SVFO (\%) } \\
\text { Ambos híb. }\end{array}$} & \multicolumn{2}{|c|}{ DAFS (dias) ** } & \multirow{2}{*}{$\begin{array}{c}\text { AACPD } \\
\text { Ambos híb. }\end{array}$} \\
\hline & & Ag 03 & HI 358 & \\
\hline Agosto & $34,26 c^{*}$ & 120,98 a & 105,32 c & 686,64 bc \\
\hline Setembro & $15,78 \mathrm{a}$ & $108,53 \mathrm{c}$ & $112,77 \mathrm{~b}$ & 521,84 a \\
\hline Outubro & $47,02 \mathrm{~d}$ & 124,74 a & 129,96 a & $1435,46 \mathrm{~d}$ \\
\hline Novembro & $33,18 \mathrm{c}$ & $73,16 \mathrm{~d}$ & $70,39 \mathrm{~d}$ & $593,13 a b$ \\
\hline Fevereiro & $27,18 b$ & $114,93 \mathrm{~b}$ & $132,29 \mathrm{a}$ & 765,16 c \\
\hline CV (\%) & 12,09 & \multicolumn{2}{|c|}{2,37} & 13,98 \\
\hline DMS & 7,81 & \multicolumn{2}{|c|}{5,32} & 229,54 \\
\hline
\end{tabular}

* Médias seguidas da mesma letra na linha não diferem entre si pelo teste Tukey (p>0,05). ** Interação entre fator A (épocas) e D (híbridos) significativa pelo teste Tukey $(\mathrm{p}<0,05)$ e "A" é desdobrado dentro de "D". 
estádio reprodutivo de início de enchimento dos aquênios com baixa severidade de ocorrência da doença até então; após a injúria foliar ocasionada pelo granizo, a severidade se elevou rapidamente. Consequentemente, a SVFO e a AACPD foram altas, e o DAFS, em funçấo da severidade se elevar somente no final do ciclo, foi também alto (Tabela 2). Na época de novembro também houve injúria foliar em função do granizo ocorrido, impedindo que se prosseguissem as avaliaçóes de IAF, o que afetou principalmente o valor de DAFS. Portanto, pode-se inferir que as épocas com maior ocorrência de doenças no ano agrícola 2008/2009 foram de outubro e novembro, atrelado em parte à injúria foliar em função do granizo. Conforme Muro et al. (2001) danos foliares no girassol podem reduzir a resistência da planta e permitir a entrada de patógenos nos seus tecidos, afetando assim a produtividade da cultura.

No ano agrícola de 2009/2010, não houve interação (AxD) significativa para nenhuma das variáveis estudadas. Ressalta-se que este ano agrícola foi de El Niño, com maior ocorrência de chuvas principalmente no último trimestre de 2009, o que favoreceu a severidade de ocorrência de doenças. A interação não foi significativa para nenhuma das três variáveis estudadas. Em janeiro, observou-se o menor valor de SVFO, não diferindo de dezembro, enquanto o maior valor ocorreu na época de outubro, que náo difere de novembro (Tabela 3). Semelhantemente, a menor AACPD ocorreu para as épocas de dezembro e janeiro, não diferindo entre si, e o maior valor foi na época de novembro, o qual não difere de outubro. O DAFS apresentou maior valor para a época de dezembro, não diferiu de janeiro. A pior época foi a de outubro, com menor DAFS, não diferindo da época de novembro (Tabela 3). Nas primeiras épocas de semeadura, as chuvas foram muito frequentes, com ocorrência de excesso hídrico prolongado, o que dificultou a germinação e o estabelecimento da cultura, afetando significativamente o híbrido $\mathrm{Hl}$ 358 nas duas primeiras épocas de semeadura (início de agosto e início de setembro), sendo suas parcelas perdidas.

No ano agrícola de 2010/2011, com apenas duas épocas de semeadura avaliadas, houve interação significativa apenas para DAFS. O maior valor de DAFS ocorreu para a época de novembro, diferindo da época de dezembro, tanto para o híbrido Ag 03 quanto para o híbrido Hl 251 (Tabela 4). A SVFO e a AACPD diferiram estatisticamente entre as duas épocas, ambas com o menor valor para a época de novembro.

Uma visão mais ampla da severidade de ocorrência de doenças em função da época de semeadura do girassol, incluindo os valores obtidos nos quatro anos de experimentos, pode ser visualizada na figura 1 . Observa-se que a média dos anos normais e de La Niña (2007/2008, 2008/2009 e 2010/2011) representa uma tendência de aumento da SVFO e da AACPD das primeiras para as épocas tardias, enquanto o DAFS tendeu a diminuir, assim como ocorre para as semeaduras mais tardias no Estado do Paraná (Leite et al., 2006). Esse resultado é coerente pelo fato de que os valores da SVFO e da AACPD (quanto menor, melhor) possuem sentidos opostos aos valores de DAFS (quanto maior, melhor), provavelmente, em função das condiçóes meteorológicas menos favoráveis durante a fase reprodutiva. Entretanto, para o ano agrícola de

Tabela 3. Severidade final observada (SVFO), dias de área foliar sadia (DAFS) e área abaixo da curva de progresso da doença (AACPD) para a mancha de Alternária e septoriose na cultura do girassol, em diferentes épocas de semeadura dos híbridos Aguará 03 (Ag 03 ) e Hélio 358 (Hl 358). Santa Maria, ano agrícola 2009/2010

\begin{tabular}{lccc} 
Época & SVFO (\%) & DAFS (dias) & AACPD \\
\hline Outubro & Ambos os híbridos & Ambos os híbridos & Ambos os híbridos \\
\hline Novembro & $52,61 \mathrm{~b}^{*}$ & $43,59 \mathrm{c}$ & $1975,46 \mathrm{~b}$ \\
Dezembro & $46,47 \mathrm{~b}$ & $50,86 \mathrm{bc}$ & $2106,21 \mathrm{~b}$ \\
Janeiro & $34,92 \mathrm{a}$ & $86,09 \mathrm{a}$ & $1135,42 \mathrm{a}$ \\
CV (\%) & $33,65 \mathrm{a}$ & $72,99 \mathrm{ab}$ & $1222,83 \mathrm{a}$ \\
DMS & 11,30 & 29,31 & 6,98 \\
\hline
\end{tabular}

${ }^{*}$ Médias seguidas da mesma letra na linha não diferem entre si pelo teste Tukey $(\mathrm{p}>0,05)$.

Tabela 4. Severidade final observada (SVFO), dias de área foliar sadia (DAFS) e área abaixo da curva de progresso da doença (AACPD) para a mancha de Alternária e septoriose na cultura do girassol, em diferentes épocas de semeadura dos híbridos Aguará 03 (Ag 03) e Hélio 251 (Hl 251). Santa Maria, ano agrícola 2010/2011.

\begin{tabular}{|c|c|c|c|c|}
\hline \multirow{2}{*}{ Época } & \multirow{2}{*}{$\begin{array}{c}\text { SVFO (\%) } \\
\text { Ambos híb. }\end{array}$} & \multicolumn{2}{|c|}{ DAFS(dias) ** } & \multirow{2}{*}{$\begin{array}{c}\text { AACPD } \\
\text { Ambos híb. }\end{array}$} \\
\hline & & Ag 03 & HI 251 & \\
\hline Novembro & $23,69 a^{*}$ & $108,10 \mathrm{a}$ & 80,44 a & 519,49 a \\
\hline Dezembro & $29,50 \mathrm{~b}$ & $77,58 \mathrm{~b}$ & $71,99 \mathrm{~b}$ & $742,34 b$ \\
\hline CV (\%) & 18,01 & \multicolumn{2}{|c|}{3,65} & 27,57 \\
\hline DMS & 7,38 & \multicolumn{2}{|c|}{4,75} & 268,03 \\
\hline
\end{tabular}

* Médias seguidas da mesma letra na linha não diferem entre si pelo teste Tukey ( $p>0,05)$. ${ }^{* *}$ Interação entre fator A (épocas) e D (híbridos) significativa pelo teste Tukey $(\mathrm{p}<0,05)$ e "A" é desdobrado dentro de "D". 
2009/2010, sob efeito de El Nińo, ocorreram altos valores de severidade das doenças foliares já nas primeiras épocas, diminuindo com as épocas mais tardias. Mesmo assim, os valores de SVFO e AACPD foram mais elevados que em anos normais ou de La Ninã (na maioria das épocas), enquanto o DAFS foi menor. Segundo Loose et al. (2010), na região pampeana argentina os rendimentos de girassol tendem a ser reduzidos em anos sob El Niño, que são anos mais chuvosos, principalmente em função das doenças na cultura, o que pode explicar o resultado apresentado.

Em anos sem El Niño (Figura 1a), verifica-se na época de setembro a menor SVFO, com média de $14,6 \%$ e desvio-padrão de $2,4 \%$, ou seja, a severidade é baixa e varia pouco entre anos. A pior época em relação a SVFO das doenças foi a de janeiro, com valor médio de 50,0\% e desvio-padrão de 4,8\%. Quanto maior o desvio-padrão, maior é a variação da severidade entre anos, ou seja, dependendo das condiçóes meteorológicas a severidade pode ser bem maior ou menor. Já para o ano sob efeito de El Niño (Figura 1b) nas épocas de agosto e setembro, verificaram-se os maiores valores de SVFO, 56,3\% e 58\% respectivamente, tendo uma pequena redução nas épocas subsequentes. As épocas de agosto e setembro são as mais recomendadas para a semeadura do girassol no Rio Grande do Sul (Leite et al., 2007), porém, em relação às doenças ocorrem diferenças entre os anos. Houve menor incidência de doenças nessas épocas em anos normais e de La Nińa (Figura 1a), o que não ocorre em ano de El Niño (Figura 1b).

Os valores de DAFS foram maiores para as duas primeiras épocas de semeadura, ou seja, a duração da área foliar sadia é maior para essas duas épocas (Figura 1c). A época de agosto teve o maior DAFS médio, de 113,53 dias com desvio-padrão de 12,7 dias, enquanto na época de setembro notou-se DAFS médio de 103,36 dias com
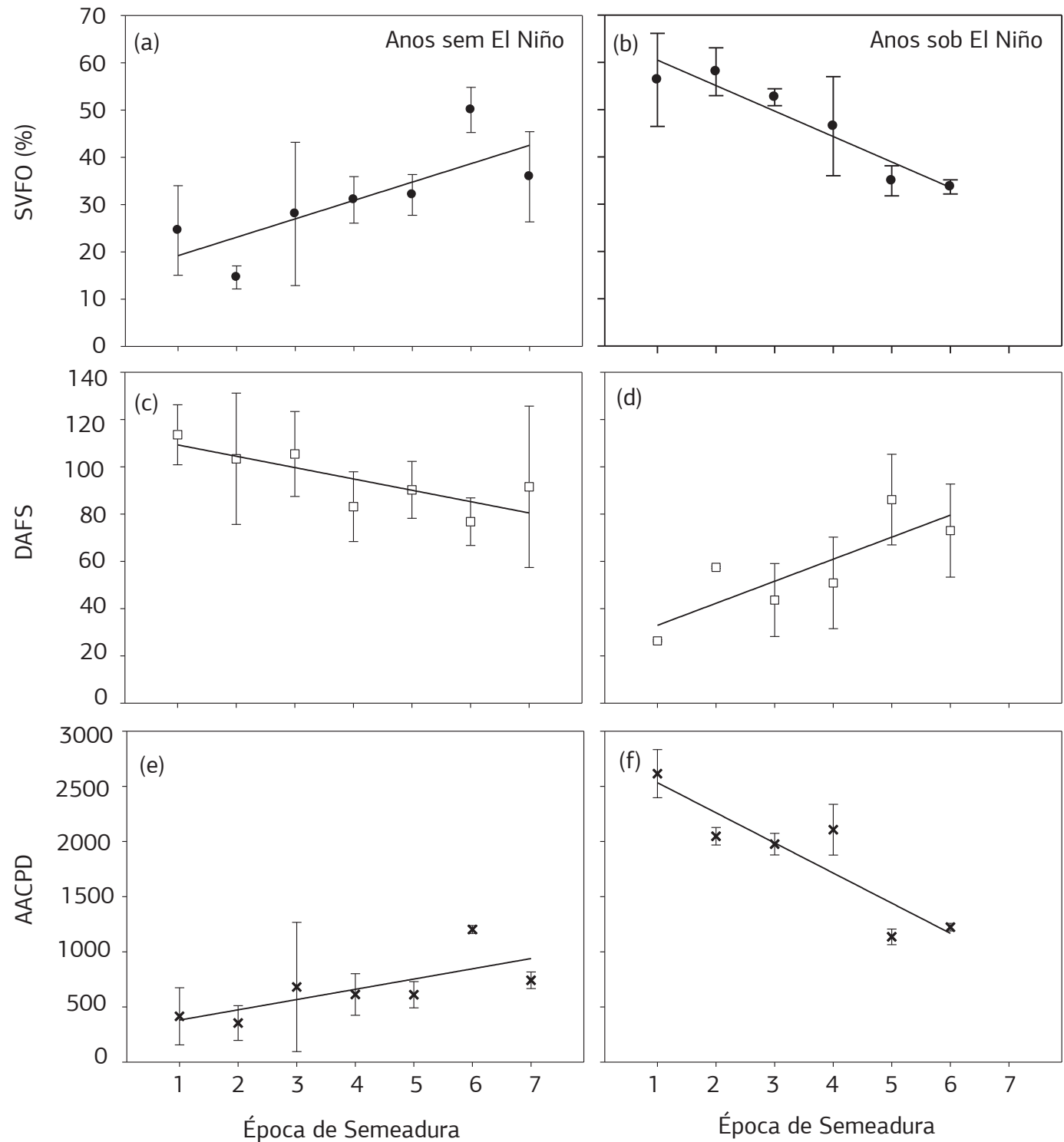

Figura 1. Média, desvio-padrão e tendência de: severidade final observada (a, b), dias de área foliar sadia (c, d) e área abaixo da curva de progresso da doença (e, f) em função das épocas de semeadura da cultura do girassol de inicio de agosto (1) a início de fevereiro (7), para anos de La Niña ou normais (a, c, e) e para ano sob efeito de El Niño (chuva acima da normal) (b, d, f). Santa Maria, 2011. 
desvio- padráo de 27,8 dias. Os menores valores ocorreram para as épocas de novembro e janeiro. No ano sob El Niño (Figura 1d), semelhante à SVFO, observou-se no DAFS os piores resultados para as primeiras épocas de semeadura.

A evoluçáo da severidade da doença dada pela AACPD para anos sem El Nińo pode ser visualizada na figura $1 \mathrm{e}$. Nota-se que nas duas primeiras épocas de semeadura a evolução da severidade da doença é baixa, girando em torno de 400, com baixo desvio-padráo. A época de janeiro tem a maior AACPD média, 1201, com um desvio- padrão baixo. $\mathrm{Na}$ AACPD há tendência de diminuição com a época de semeadura para ano de El Nińo (figura 1f).

Verifica-se que a AACPD tem correlaçáo $\left(\mathrm{R}^{2}=0,61\right)$ com a quantidade de precipitação pluvial acumulada ocorrida, em que as maiores precipitaçóes resultam em maior AACPD (Figura 2a). Dessa forma, observa-se que esse elemento meteorológico é importante para a manutenção das condiçóes de umidade e molhamento foliar necessários à ocorrência das doenças (SEnTELHas et al., 1996), bem como atua na dispersão dos inóculos. Verificou-se também a correlação da AACPD com a média da temperatura máxima diária, indicando coeficiente de determinação $\mathrm{R}^{2}=$ 0,52 (Figura 2b). A correlação entre a AACPD e a média da temperatura do ar média diária tem o mesmo comportamento, embora não tão significativo como a anterior, com $\mathrm{R}^{2}=0,29$ (Figura 2c). O resultado indica que em épocas mais quentes aumenta a probabilidade de alta severidade de ocorrência de doenças. Considerando-se que para a mancha de Alternária, a ocorrência é severa em uma ampla faixa de variação de temperatura, é justificada sua ocorrência em todas as épocas de semeadura (Leite e Amorim, 2002a). Porém, ainda assim, verifica-se uma distribuiçáo de pontos bastante deslocada em relaçáo à linha de tendência. Dessa maneira, subentende-se que tanto a variável precipitação pluvial acumulada quanto a temperatura do ar, quando analisadas isoladamente não conseguem explicar os valores de severidade, sendo a AACPD dependente das duas variáveis. Essa constatação se deve às interaçôes existentes entre esses elementos meteorológicos que determinam as condiçóes de umidade do ar e por consequência a ocorrência de molhamento foliar (HeLdwein et al., 2007) que são condiçôes ambientais predisponentes à ocorrência das doenças avaliadas neste trabalho, que apresentam consideráveis variaçóes com as épocas de semeaduras (AMABiLE et al., 2002).

\section{CONCLUSÃO}

As épocas de semeadura de início de agosto até início de setembro são as épocas em que ocorre menor severidade de ocorrência de doenças no girassol cultivado em Santa Maria (RS). Semeaduras tardias, principalmente no início de janeiro são mais propícias à alta severidade de ocorrência de doenças no girassol, em função das condiçóes ambientais predisponentes.
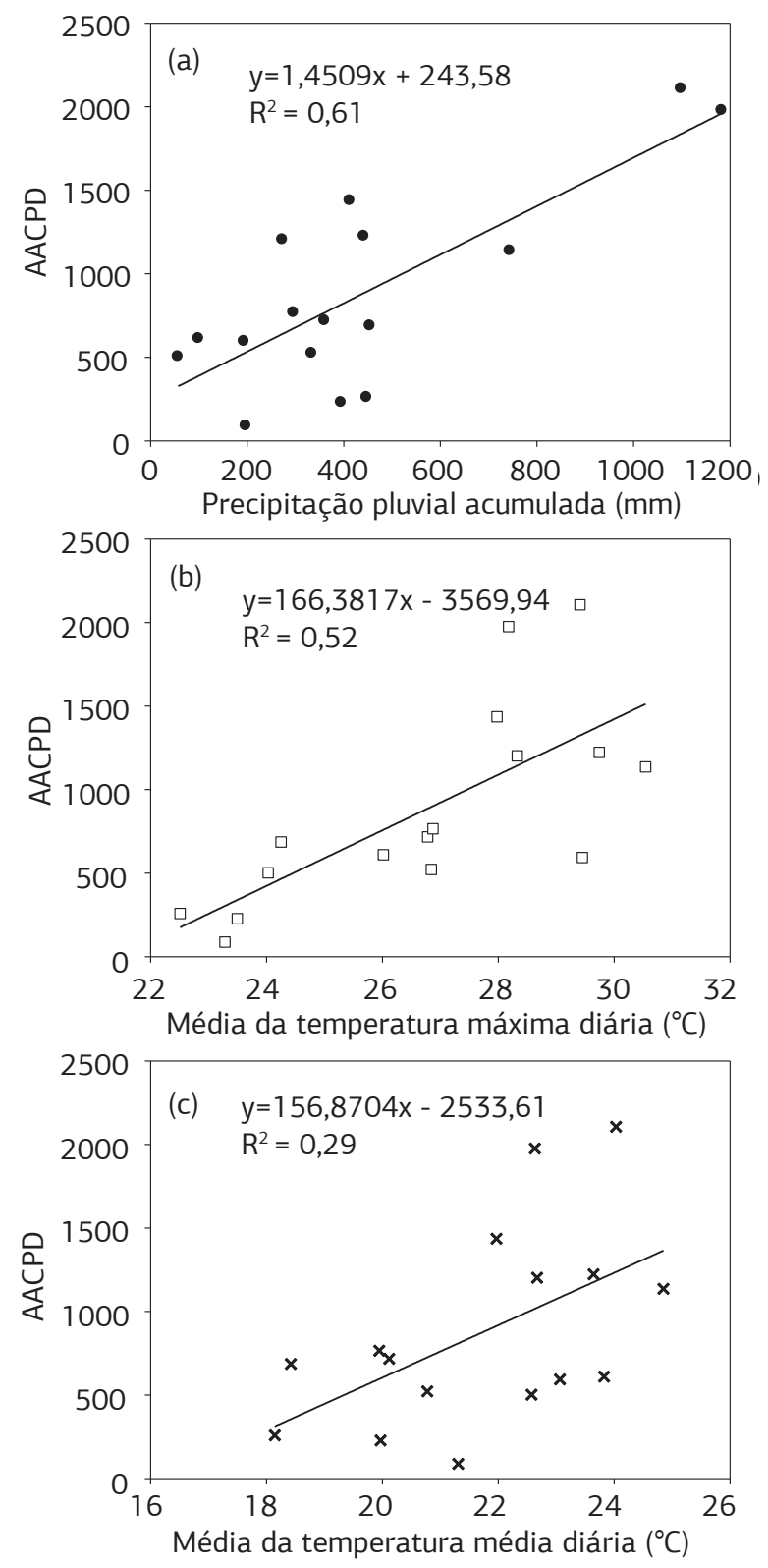

Figura 2. Relação entre as variáveis ambientais, precipitação pluvial acumulada (a), média da temperatura do ar máxima diária (b) e média da temperatura do ar média diária (c), e a área abaixo da curva de progresso da doença (AACPD) de mancha de Alternária e septoriose na cultura do girassol. Santa Maria, 2011.

Em anos sob influência de El Niño, que geralmente registram elevadas precipitaçóes pluviais, ocorre maior severidade de ocorrência de doenças em relação a anos de La Niña e neutros, sendo de alto risco o cultivo do girassol nesses anos na regiấo central do Rio Grande do Sul.

\section{AGRADECIMENTOS}

Os autores agradecem às instituiçôes CAPES, CNPq e FAPERGS pela concessão de bolsas a alguns dos autores. 


\section{REFERÊNCIAS}

AGRIOS, G.N. Environmental effects on the development of infectious plant disease. In: AGRIOS, G.N. Plant Pathology. 5.ed. San Diego: Academic Press, 2004. cap.7, p.251-262.

AMABILE, R.F.; VASCONCELLOS, C.M.; GOMES, A.C. Severidade da mancha-de-alternária em cultivares de girassol na região do Cerrado do Distrito Federal. Pesquisa Agropecuária Brasileira, v.37, p.251-257, 2002.

BLOCK, C.C. Evaluation of wild Helianthus annuus for resistance to septoria leaf blight. Proceedings Sunflower Research Workshop, 2005. Disponível em: http://www.sunflowernsa.com/research/ research-workshop/documents/Block_Septoria_05.PDF

BOSCO, L.C.; HELDWEIN, A.B.; LUCAS, D.D.P.; TRENTIN, G.; GRIMM, E.L.; LOOSE, L.H. Sistema de previsão de ocorrência de requeima em clones de batata suscetíveis e resistentes. Ciência Rural, v.39, p.1024-1031, 2009.

CAMPBELL, C.L.; MADDEN, L.V. Forecasting plant diseases. In: CAMPBELL, C.L.; MADDEN, L.V. Introduction to plant disease epidemiology. New York: John Wiley, 1990. cap.15, p. 423-452.

CARGNELUTTI FILHO, A.; STORCK, L. Estatísticas de avaliaçáo da precisão experimental em ensaios de cultivares de milho. Pesquisa Agropecuária Brasileira, v.42, p.17-24, 2007.

CQFS - COMISSÃO DE QUÍMICA E FERTILIDADE DO SOLO. Sociedade Brasileira de Ciência do Solo. Manual de adubação e calagem para os Estados do Rio Grande do Sul e Santa Catarina. 10.ed. Porto Alegre, 2004. 400p.

CONAB. Série histórica de produçấo e área plantada: safras 1976/77 a 2010/2011. Brasília. Ministério da Agricultura, Pecuária e Abastecimento, 2011. Disponível em: <http://www.conab.gov.br/ conteudos.php?a=1253\&t=2> Acesso em 14/4/2011.

DALLAGNOL, A.; VIEIRA, O.V.; LEITE, R.M.V.B.C. Origem e histórico do girassol. In: Girassol no Brasil. 1.ed. Londrina: Embrapa Soja, 2005. cap.1, p. 1-14.

DUDIENAS, C.; UNGARO, M.R.G.; MORAES, S.A. Alternaria disease development under tropical conditions. Helia, v.21, p.6372. 1998.

EMBRAPA. Centro Nacional e Pesquisa em Solos. Sistema Brasileiro de Classificação de Solos. Brasília: Embrapa - SPI; Rio de Janeiro: Embrapa Solos, 2006. 306p.

HELDWEIN, A.B; CONTERATO, I.F.; TRENTIN, G.; NIED, A.H. Princípio para implementar alertas agrometeorológicos e fitossanitários. In: CARLESSO, R; PETRY, M.T.; ROSA, G.M. da; HELDWEIN, A.B. Usos e benefício da coleta automática de dados meteorológicos na agricultura. 1.ed. Santa Maria: Editora UFSM, 2007. cap.5, p.115-134

HELDWEIN, A.B; BURIOL, G.A.; STRECK, N.A. O clima de Santa Maria. Ciência \& Ambiente, v.38, p.43-58, 2009.

HUBER, L.; GILLESPIE, T.J. Modeling leaf wetness in relation to plant disease epidemiology. Annual Review of Phytopathology, v.30, p. 553-577, 1992.
LEITE, R.M.V.B.C. Manejo de doenças no girassol. In: LEITE, R.M.V.B.C.; BRIGHENTI, A.M.; CASTRO, C. Girassol no Brasil. 1. ed. Londrina: Embrapa Soja, 2005. cap.17, p.501-546.

LEITE, R.M.V.B.C.; AMORIM, L. Influência da temperatura e do molhamento foliar no monociclo da mancha de Alternária em girassol. Fitopatologia Brasileira, v.27, p. 193-200, 2002a.

LEITE, R.M.V.B.C.; AMORIM, L. Elaboração e validação de escala diagramática para mancha de Alternária em girassol. Summa Phytopathologica, v.28, p.14-19, 2002b.

LEITE, R.M.V.B.C.; AMORIM, L.; BERGAMIN FILHO, A. Relationships of disease and leaf area variables with yield in the Alternária helianthi-sunflower pathosystem. Plant Pathology, v.55, p.73-81, 2006.

LEITE, R.M.V.B.C.; CASTRO, C.; BRIGHENTI, A.M.; OLIVEIRA, F.A. de; CARVALHO, C.G.P.; OLIVEIRA, A.C.B. Indicaçóes para o cultivo de girassol nos Estados do Rio Grande do Sul, Paraná, Mato Grosso do Sul, Mato Grosso, Goiás e Roraima. Londrina: Embrapa Soja, 2007. 4p. (Comunicado Técnico, 78)

LOOSE, L.H.; LONG, M.E.F.; CARNELOS, D.; MURPHY, G.M. Variabilidade dos rendimentos de girassol na Argentina em função da variabilidade climática interanual. Revista de la Facultad de Agronomia - UBA, v.30, p.169-178, 2010.

MALDANER, I.C.; HELDWEIN, A.B.; LOOSE, L.H.; LUCAS, D.D.P.; GUSE, F.I.; BORTOLUZZI, M.P. Modelos de determinação não-destrutiva da área foliar em girassol. Ciência Rural, v.39, p.1356-1361, 2009.

MURO, J.; IRIGOYEN, I.; MILITINOC, A.F.; LAMSFUS, C. Defoliation effects on sunflower yield reduction. Agronomy Journal, v.93, p.634-637, 2001

ORTA, A.H.; ERDEM, T.; ERDEM, Y. Determination of water stress index in sunflower. Helia, v.25, p.27-38, 2002.

RIBEIRO, I.J.O.; FILHO, O.P.; SOAVE, J.; CERVELLINI, J.S. Ocorrência de Alternaria helianthi (Hansf.) Tubaki \& Nishibara sobre girassol. Bragantia, v.33, p.81-85, 1974.

SENTELHAS, P.C.; PEZZOPANE, J.R.M.; UNGARO, M.R.G.; MORAES, S.A.; DUDIENAS, C. Aspectos climáticos relacionados à ocorrência da mancha de alternária em cultivares de girassol. Fitopatologia Brasileira, v.21, p.464-469, 1996.

SIIA. Estimaciones y Estadísticas. Sistema Integrado de Información Agropecuaria. Ministerio de Producción. Secretaría de Agricultura, Ganadería, Pesca y Alimentos de la Nación Argentina. Disponível em: [http://190.220.136.179/index.php/series-portema/agricultura], 2010.

SILVEIRA, J.M.; CASTRO, C.; MESQUITA, C.M.; PORTUGAL, F.A.F. Semeadura e manejo da cultura de girassol. In: LEITE, R. M. V. B. C.; BRIGHENTI, A. M.; CASTRO, C. de. (Ed). Girassol no Brasil. [Londrina]: Embrapa Soja, 2005. p. 375-406.

WAGGONER, P.R.; BERGER, R.D. Defoliation disease and growth. Phytopathology, v.77, p.393-398, 1987. 